\title{
¿ Representaciones sobre la Patagonia y sus habitantes originarios en los textos escolares. 1886-1940
}

\author{
Mirta Teobaldo ${ }^{2}$ \\ M aría Andrea Nicoletti ${ }^{3}$
}

\section{Introducción}

a Patagonia, como construcción territorial, reflejo y refracción del Lconjunto social y los intereses políticos, ha devenido en el transcurso del tiempo en "tierra mítica".

En el marco del conflictivo proceso histórico de su incorporación a la N ación (1879-1885), la Patagonia, como otros territorios nacionales fue el espacio sobre el cual el Estado, a partir de la creación de un sistema educativo centralizado, impuso políticas de "argentinización" y de "homogeneización" como estrategia para asegurar la soberanía nacional.

En este sentido, uno de los instrumentos privilegiados del curriculum escriturado fueron los textos escolares que sirvieron para la construcción y socialización de imágenes oficiales y estandarizadas del territorio nacional. De uso obligatorio en la escuela, reflejaban el proyecto hegemónico que tenía como misión difundir una cultura para construir una nación.

Sin embargo, la representación de la Patagonia a través de los libros de texto, es un tema escasamente estudiado.

Nos proponemos analizar en este trabajo, cómo los textos escolares reflejaron una visión nacional describiendo a la Patagonia por medio de imágenes contrapuestas que manifestaban en su espacio

1 Este trabajo forma parte del Proyecto: "Libros de texto. Imágenes y representaciones: La construcción de la Patagonia en el imaginario escolar. Río Negro y Neuquén (1884-1957)"dirigido por Mirta Teobaldo y Amelia B. García en la Facultad de Ciencias de la Educación de la Universidad Nacional del Comahue.

2 Universidad Nacional del Comahue. E-mail: mirteobaldo@infovia.com.ar

3 CONICET/Univ. Nac. Del Comahue. E-mail: navarronicoletti@ciudad.com.ar 
"lo civilizado y lo incivilizado e inexplorado", la belleza y la riqueza contra la infertilidad y la aridez y su potencial productivo y de futuro nacional. Por otro lado, el tratamiento de sus habitantes originarios, nos remite al indígena como "salvaje" y "enemigo de la civilización" en un espacio "vacío" y "desierto" y al indígena "paleontologizado" y ahistórico, en un espacio natural con potencial productivo. Estas representaciones están vinculadas a dos ideas relacionadas con las políticas del Estado sobre la Patagonia: una con el plano territorial: la idea de "desierto" y "vacío" y la otra, con el plano de sus habitantes: la idea de "salvajismo" y "barbarie". Ideas que legitiman la conquista y el exterminio de sus habitantes originarios.

\section{Los textos escolares como constructores de representaciones}

Los textos escolares nos permiten profundizar el análisis de aquellas imágenes oficiales que sobre el territorio nacional y sus habitantes circulaban en el imaginario social de la época. Los textos no sólo circulaban en el ámbito escolar, sino que también estaban destinados a potenciales sujetos lectores, a un sujeto lector ampliado, porque el libro escolar era a menudo el único material de lectura en el ámbito familiar (Cucuzza y Pineau, 2002). Los mismos autores advertían con frecuencia, en la introducción de su obra, no sólo a los maestros, sino también a los padres, sobre la forma de presentación de los contenidos. De este modo, se extendía a la sociedad la imposición de referentes patrióticos que actuaban, como aglutinadores y al mismo tiempo como diferenciadores. Aglutinadores porque enfatizaban la importancia en la construcción de las identidades nacionales y la conceptualización básica del territorio como definición última de los límites de la ciudadanía, y diferenciadores porque reconocían la existencia de márgenes de exclusión identificados con todo aquello que no era capaz de civilización, naturalizando la marginación del 0 tro mediante políticas combinadas de exclusión por fusión y exterminio (Q uijada 2000:32).

A partir de la selección realizada basamos fundamentalmente nuestro análisis en las siguientes representaciones sobre la Patagonia: La construcción del espacio como Territorio, en clave paisajística, productiva y de soberanía nacional; la construcción del indígena como "salvaje" y "enemigo de la civilización" en un espacio "vacío" 
y desierto; como "bárbaro" en un territorio transformado y "arqueologizado", "paleontologizado" y ahistórico, en un espacio natural con potencial productivo.

Para el análisis de la construcción del Territorio y sus habitantes, hemos seleccionado un corpus documental de treinta y un textos de editoriales oficiales y de la Congregación salesiana. La incorporación de textos salesianos obedece al protagonismo y presencia monopólica de las escuelas de la Congregación en la región. Los Salesianos contaban con una editorial que elaboraba sus propios textos de acuerdo a las normas oficiales, aunque supervisados por sus autoridades internas (Programas escolares 1907). Los libros analizados pertenecen a las escuelas del Estado y a la Congregación salesiana.

El corpus documental contiene libros de lectura, M anuales escolares y Revistas de formación docente, como La O bra y la Revista de Instrucción primaria. Esto nos posibilita el análisis de diferentes construcciones discursivas sobre un mismo tema: el territorio patagónico y sus habitantes.

Si bien el corte cronológico que definimos comprende el período territoriano, (1880-1957) hemos seleccionado, ante la inexistencia de textos de edición regional, aquellos textos que contienen temas patagónicos elaborados y editados en Buenos Aires entre 1886 y 1940 y que circularon por las escuelas públicas y salesianas de la región. 0 ptamos en este trabajo no abordar el período de los gobiernos peronistas (1945-1955), debido a las siguientes razones: 1) no haber hallado hasta el momento de la elaboración del presente artículo un corpus lo suficientemente significativo que de cuenta de la temáticas que nos interesan para abordar nuestro objeto; 2 ) entendemos que este período marca un cambio fundamental en las políticas sobre el territorio y sus habitantes y que por lo tanto merecen un análisis particularizado que será objeto de estudios posteriores.

En ese sentido, durante el extenso período del territorio, las políticas indígenas que partieron de los organismos centrales de gobierno parecen a simple vista un conjunto de respuestas espasmódicas que buscaban resolver o más bien sacarse de encima la "cuestión indígena". Sin embargo, Briones y Delrio interpretan que estas medidas formaron parte de una "acción estatal de dominación en un complejo campo de intereses y negociaciones" (Briones y Delrio 2002). Delrio observa en este largo camino que se inicia con la incorporación forzosa de los pueblos indígenas tras las campañas militares (1872-1885), 
un momento de construcción de la categoría "ciudadano indígena" o "indígena argentino" (1885-1904) bajo criterios homogenizadores, pero también diferenciadores que buscan, en una suerte de profusa legislación sobre tierras, "civilizar" y "sedentarizar" a lo que el Estado consideraba como "elemento remanente en extinción". El discurso que "invisibiliza" al indígena, se manifiesta en un período que coincide con la etapa más fuerte de expropiaciones de tierras a los pueblos originarios y a un discurso político de "homogeneidad racial de la Nación" ante una heterogeneidad étnica que se considera ya superada en el pasado (1904-1916). Esta "asimilación" forzada, que los libros de texto señalan como la integración del indígena a la civilización, se profundiza en los períodos de presidencias radicales, como señala Delrio, cuando el Estado se sitúa como mediador entre la sociedad civil y los indígenas sobre los que construye miradas diferenciales y sitúa en los márgenes relegándolos y acorralándolos ante el avance de los alambrados de los poderosos y de las fuerzas de seguridad. El período nacionalista (1930-43) y la crisis económica del '30 con la continuidad en las expropiaciones de tierras, reforzaron esta "asimilación forzada" con la migración de los indígenas a las ciudades y la "invisibilización". El discurso hegemónico nacionalista retoma la condición de "argentinidad" "invocada como excluyente (o incluyente)" (Delrio 2005:252) porque como señala el texto Nuestra Tierra, los indígenas que quedan "son muy pocos y no viven en sus toldos como antes sino en las estancias o chacras, sirviendo de peones los hombres y en los quehaceres domésticos las mujeres" (López de N elson 1912/16: 33).

\section{La construcción del Territorio}

Desde el proyecto hegemónico en el período de consolidación del Estado nacional, la Conquista es el acto iniciático, según los textos analizados, que funda /construye el paisaje patagónico, transformándolo de tenebroso en bello, de bárbaro a moderno.

"La campaña del desierto permitió incorporar a la civilización una extensísima zona favorable para la agricultura y la ganadería, lo que trajo como consecuencia un progreso pujante de la vida rural argentina" (Raviol 1912). 
Con ella se abre el telón y comienza una nueva argentina que ofrece espacios de magnificencia incomparable aptos para vivir y producir. En ese sentido la Patagonia, "ostenta hermosas praderas y bosques en las faldas andinas y en las inmediaciones de ríos y lagos " (Raviol 1912).

Las investigaciones referidas al análisis de las representaciones sobre la Patagonia, realizadas por la geografía, la historia, la arqueología, la etnografía nos dan algunas pistas. En una primera etapa histórica que recorre la época colonial hasta la conquista militar de 1879, las representaciones están vinculadas a dos ideas relacionadas, una con el plano territorial: la idea de "desierto" y "vacío" y la otra, con el plano de sus habitantes: la idea de "salvajismo" y "barbarie". Esta primera mirada se constituye, según Navarro Floria, en la plataforma que legitima la política de conquista. La idea de "vacío" se trasluce claramente, por ejemplo, en las políticas territorianas, sobre todo en la Ley de Territorios (1532 en 1884), que predomina sobre otros proyectos y diseños territoriales (M itre en 1872 y Pellegrini en 1900) (Navarro Floria, 2001 y 2002). En este sentido, hemos observado que las etapas correspondientes al discurso científico enunciado no tienen un correlato punto a punto con el discurso escolar que visualizamos a través de los textos, por el contrario la trasposición didáctica operó yuxtaponiendo las categorías.

La fuerte recurrencia de ciertas metáforas, como las del "desierto", y el "espacio vacío", deben entenderse como la institucionalización de una imagen, de una mirada particular acorde con el discurso científico que contribuía a la internalización del territorio como uno de los componentes de la ideología colectiva nacional; sólo el territorio definía las fronteras de la inclusión y si bien la idea de "desierto" estaba puesta en el referente empírico territorial, el "vacío" era asumido como la ausencia de "civilización", legitimando la conceptualización del espacio como espacio abandonado de cultura.

En la descripción de la "conquista del desierto" en el texto de L. Raviol, Compendio de Geografía (1912), adentrarse en el territorio constituía una "aventura temeraria". Plagada de "salvajes" que atacaban y tomaban cautivos, el espacio es un "desierto" jalonado por postas "separadas por muchas leguas de camino que no eran más que una simple huella de vehículos en medio del desierto". Con Alsina se inició, según el texto, un nuevo período: "la nueva lucha contra los salvajes por medio de la cual Roca logró el triunfo definitivo sobre 
los indígenas del sur". Pero fundamentalmente, el texto destaca que sin la "conquista del desierto, la obra hubiera sido imposible: la incorporación de mas de quince mil leguas de territorio incorporado al patrimonio nacional y al progreso."

El Estado central diseña los Territorios Nacionales, utilizando los textos escolares, entre otros recursos, para presentar y exponer su "territorialidad". En los textos de Geografía salesianos se percibe el espacio en el que prevalecen los espacios desconocidos y contrastantes en clave paisajística: triste y desolado/Suiza Argentina (N euquén), extensa Ilanura/País del Diablo (Río N egro), árida/fértil (Chubut), mucha Iluvia y vientos fuertes/extensos y hermosos lagos (Santa Cruz), Ilanura estéril/bosques espesos siempre verdes (Tierra del Fuego) (Compendio de Geografía $3^{\circ}$ Ed, 1911:128-130).

La imagen contrapuesta de la Patagonia, en los primeros textos de Geografía previos a 1879, nos muestra un espacio "indiscutiblemente sometido a la soberanía nacional como una tierra radicalmente desconocida y vacía" (Navarro Floria 2001). En este sentido, la imagen de la Patagonia reflejada en esos textos no responde a la transposición de los conocimientos científicos de la época sino más bien a la funcionalidad política que buscaba "canonizar una imagen unificada del país y de su territorio" (Navarro Floria 2001:149).

Tal como señala Quintero, hasta la década del '20 "los programas de geografía no recurrían a ningún concepto de región para proponer imágenes sobre las diferencias internas del territorio argentino", sino a los "aspectos generales del país" que significaban un extenso listado descriptivo de enunciaciones.

La división por excelencia era la política, que agrupaba provincias y territorios nacionales en un esquema inalterable: Provincias del Litoral, Centrales, Andinas y del Norte, un distrito federal y diez gobernaciones o territorios nacionales divididos en Gobernaciones del Norte (M isiones, Chaco, Formosa, Los Andes) y Gobernaciones del Sud (La Pampa, N euquén, Río N egro, Chubut, Santa Cruz y Tierra del Fuego).

Como veremos a continuación esta ha sido la matriz que recorre también la caracterización de cada uno de los territorios patagónicos y contrapone los términos fértil/infértil, conocida/desconocida y explorada/inexplorada, mostrándonos a una Patagonia de principios de siglo inserta en la clásica conceptualización: "civilizada/incivilizada". 
Por ejemplo, en los textos de Geografía salesianos (Compendio y Pequeña Geografía), N euquén es en su parte oriental Ilana, triste y desolada pero en su parte occidental es la Suiza Argentina ( 3 a ed., p.128). Chubut en su parte oriental es "Ilana y árida" y en su parte occidental es "fértil y aun inexplorada" (3a ed., p. 130). Santa Cruz en la parte oriental "llueve mucho y los vientos son fuertes y frecuentes, pero en la región occidental abundan extensos y hermosos lagos" (3a ed., p. 130). En Tierra del Fuego la zona oriental es "una extensa Ilanura estéril y desprovista de árboles y de nieves perpetuas pero en la occidental hay bosques espesos siempre verdes" (3a ed., p. 131). En el caso de Río N egro, si bien no se explicita la división entre oriental y occidental que hemos observado en los otros territorios, sí encontramos la dualidad manifiesta en el paisaje, entre una llanura extensa, "cubierta de pastos y arbustos y la zona comprendida entre los ríos Negro y Colorado que ha sido denominada País del Diablo por la aridez de una gran parte de su suelo" ( $3^{\text {a }}$ ed., p. 130).

En los textos oficiales como N uestra Tierra (circa 1912) la descripción del paisaje, sigue la misma matriz de contraposición de zonas áridas y fértiles, pero la comparación se efectúa en este caso entre el norte y el sur, a diferencia de los textos salesianos que la realizan entre oriente y occidente. N euquén y La Pampa corresponden al norte mientras Río N egro, Santa Cruz y Chubut pertenecen al sur. En las primeras el clima es mas templado, la tierra es cultivable, los vientos menos fuertes y las lluvias mas frecuentes, debido a esto la región es rica en pastos naturales. En cambio en la segunda el clima es frío, el suelo se presenta salpicado de matas de hierbas y arbustos, duros y espinosos a causa del clima.

Los textos de G eografía oficiales y salesianos muestran la ampliación de la geografía física en secciones como: orografía, hidrografía, costas, clima, accidentes geográficos, límites, población y producción. Secciones que aparecen más ricas y detalladas en los Compendios de editorial salesiana.

Como señala Q uintero, el ingreso de las Ciencias $N$ aturales a la G eografía determinó que la G eografía física se convirtiera en

"vehículo para la difusión de sus métodos analíticos y clasificatorios. Con ellos se procuraba brindar una visión a la vez integral y sistemática de la natural eza del territorio argentino. Pero el sistema realizaba una disección temática y no regional del territorio 
argentino. Cada tema recorría los componentes de todo el conjunto (por ejemplo, ríos y cuencas, sistemas orográficos, etc.)".

Las únicas divisiones internas del territorio seguían siendo las unidades políticas (las catorce provincias y las gobernaciones). Cada división territorial merecía su propio inventario, que replicaba aproximadamente los temas de la geografía nacional:

"aspecto físico, superficie, población; capitales y agrupaciones más importantes; producciones, industrias, comercio, vías de comunicación; organización política y administrativa, educación. La descripción recorría brevemente la geografía física y se extendía en la político-económica, pero sin establecer ninguna conexión causal explícita entre ellas. En otras palabras, la geografía física no proponía una división territorial distinta a la que resultaba del diseño constitucional del Estado" (Quintero 2002:11).

Un tema recurrente en los textos de esta etapa es el problema limítrofe, especialmente con Chile, que tiene la frontera más extensa con la Argentina. La delimitación territorial definitiva fue una preocupación que emergió como una constante en los discursos nacionales sobre la soberanía territorial. Constituir claramente los límites significaba, para el Estado argentino, nacionalizar las fronteras y afianzar, de una vez y para siempre, el tema recurrente de la pertenencia de la Patagonia a la Argentina 4 .

Según Pablo Lacoste, tras la firma de los tratados de 1881 y 1902 entre Argentina y Chile se estableció un clima de cordialidad, cooperación y concordia entre ambos países que se cristalizó en sus respectivas corrientes historiográficas. $Y$ esto se demuestra en el manual para las escuelas medias de Ricardo Levene Lecciones de Historia Argentina que circuló entre 1912 y 1950, en el que se incorporó el mapa de Emilio Ravignani sobre el Virreinato del Río de la Plata, que "prioriza la frontera real y efectiva por sobre la frontera jurídica" (Lacoste 2003:203). En esta misma línea otros textos oficiales, como el Manual de Historia de la Civilización Argentina de R. Carbia (1912) justifica también, por medio de fuentes coloniales fundamentadas en

4 Este tema aun no ha sido superado. Por momentos y actualmente, aparecen en los medios de comunicación mapas pertenecientes a textos escolares chilenos, que incluyen la Patagonia en su territorio y reavivan la discusión histórica de la construcción de ambos Estados, que, con recelo, se posicionan como víctimas o usurpadores, en base a discursos nacionalistas basados fundamentalmente en una selección discrecional de fuentes coloniales. 
los trabajos de Paul Groussac, la pertenencia de la Patagonia a la Argentina, pues la misma formaba parte de la jurisdicción política del Virreinato del Río de la Plata. O tro texto oficial señalaba igualmente que el Virreinato comprendía "el actual territorio argentino" incluidos Paraguay, U ruguay, Bolivia, parte del Brasil y las islas M alvinas. En el mismo texto el autor caracteriza el "aspecto general" de la Argentina por regiones y muestra específicamente a la Patagonia como una "llanura escalonada entre los Andes y el Atlántico" (Raviol 1913).

Los textos salesianos de Geografía (Compendios de Geografía entre 1900 y 1911) sólo reflejan parcialmente esta tendencia, que seguramente fue más clara e inmediata en la Educación superior, controlada por las elites ilustradas, en el caso citado directamente por los historiadores de la Academia $\mathrm{N}$ acional de la $\mathrm{H}$ istoria. Los textos de educación primaria, escritos por maestros y destinados a un público más amplio, no reflejaban seguramente ideas que circulaban en ámbitos de acceso restringido de la información de primera mano. De esta manera, observamos en esta lectura que si bien predomina la fundamentación nacionalista basada en la extensión amplia del Virreinato y que Chile obtiene mayor extensión tras el tratado, la Argentina queda con los terrenos indudablemente mejores, cuatro lagos completos y la mitad de otros cuatro. A pesar de ser "heredera" del Virreinato "movida por leales sentimientos de paz y confraternidad, ha cedido en territorio en todos los casos sin menoscabo de su dignidad". La idea de paz y fraternidad entre los pueblos es enfatizada en un libro de lectura, mediante la reproducción de un fragmento del discurso de Mitre con la imagen de bronce del "Cristo Redentor", erigida en el límite político. "Y así como es eterna la figura que representa esa estatua, fundida en la eternidad del bronce, será eterna, también, la paz que liga a los pueblos argentino y chileno" (Capdevilla y García Belloso 1937). De la misma forma, el texto oficial Compendio de Geografía de América de L.Raviol narra la intervención del arbitraje inglés favorable a Chile en kilómetros cuadrados. Según Raviol, la Argentina aunque "quería en vez por límites las altas cumbres de la Cordillera", fue perjudicada por el laudo arbitral de 1912 que otorgó a Chile 54 mil kilómetros cuadrados de los 94 mil en litigio. 


\section{La consideración del otro}

a) En los textos oficiales

Los discursos escolares sobre los indígenas en el corpus documental seleccionado posicionan a los habitantes originarios en un espacio "vacío" y "conquistado", en el que la idea de homogeneización construye una relación de poder asimétrica y de subordinación entre el blanco y el indígena considerado, en un primer momento, como el "salvaje" e "incivilizado" que debía ser aniquilado y luego no ya como sujeto, sino como objeto arqueologizado y naturalizado.

Para los constructores de la Nación de mediados del siglo XIX, se borra el espacio mestizo colonial de la frontera sur, espacio dinámico de alta circulación social y comercial (Solís y Villalobos 2002), no admitían fronteras, espacios híbridos, espacios mestizos y culturas diferentes. El "otro" debía ser aniquilado y por lo tanto el "desierto" debía transformase en un espacio "vacío" con límites pero sin fronteras, un particular espacio de los que ya no son y de los que todavía no han llegado y es precisamente en este punto, donde la ciencia colaboraba con la política en la categorización del "otro" como "salvaje", "bárbaro" e "incivilizado" incapaces de la redención secularizada de la educación (Pratt 1997; Andermann 2000 y Navarro Floria 2001 y 2002). En esta línea ideológica el texto La Historia Argentina de los niños en cuadros (1910), al tratar la "campaña al desierto" de Juan Manuel de Rosas (1832), el indígena aparece en el texto como amenaza por lo que se justifica la campaña y la usurpación de tierras "que antes pertenecían a los indios". Resulta significativo el reconocimiento del término "pertenencia" en un contexto discursivo de conquista.

a.1) El "salvaje" en la construcción del territorio

La construcción del indígena como "salvaje" y como "bárbaro" en función de su naturaleza indómita, responde a una construcción científica determinista que excluye la posibilidad de modificación de la propia naturaleza. En los textos siguientes aparece el indígena "salvaje" asimilado al salvajismo animal al asociarlo con los aullidos del lobo en su acción contra la propiedad del "blanco": "Las tradiciones de aquel tiempo están Ilenas de episodios de valor y de espanto, cuan- 
do los indios armados a lanza, aullando como lobos, se arrojaban sobre las estancias..." (Blomberg 1925:16).

El autor "incluye una visión del presente y una visión épica del pasado" (Podgorny 1999a:142). Resulta en tal sentido significativo que en el mismo libro de lectura contenga un fragmento de Tabaré (poesía de José Zorrilla de San Martín) que reivindica a "Los indios" como "héroes" y "mártires de la patria". Pero al mismo tiempo, en otra lectura "Los Fortines" alude a los mismos como "centinelas del desierto", "guardianes de la civilización nacional" y como instrumentos que junto al fusil colaboraron con la desaparición de los "indios salvajes". "Indios" que de todos modos estaban condenados fatalmente, según la concepción evolucionista, por su misma naturaleza a la extinción física y/o a la inclusión en la civilización por la raza superior (Podgorny 1999a:143).

"Pero en la historia y en las tradiciones argentinas se ha de recordar siempre el papel que desempeñaron en la conquista de la civilización, allá en los tiempos duros y lejanos cuando la amenaza terrible del malón se cernía sobre los campos, y el estanciero, el colono vivían con el fusil al alcance de la mano..." (Blomberg 1925:16).

En Historia Argentina aparece el "salvaje" en los orígenes históricos de la Nación. Bajo el título "Naciones de Indios" el texto de C. Canepa comienza: "El territorio actual de la República Argentina estaba poblado en la época del descubrimiento por numerosas naciones de indios, más o menos salvajes de indios" (Canepa 1912:21).

Por otro lado, en el texto de Arriola, el "salvaje" procede de otros lugares, invadiendo nuestro territorio. Es significativo señalar que en él se alude al araucano como "salvaje" e invasor chileno, apelando a una imagen particular construida desde el inicio mismo de la Conquista militar (1879-1884): el chileno como enemigo nacional, como intruso que avanza sobre los límites fronterizos para ocupar la Patagonia. El salvajismo es extranjero e invasor, empuja incluso a los habitantes originarios del territorio argentino ${ }^{5}$ :

5 Este tema ha sido analizado por diferentes autores, entre los que mencionamos Walter Delrio (2005), Mirta Teobaldo y Amelia B. García (1993), Luis Alberto Romero (2004) y Pablo Lacoste (2001). 
"En la época en que los españoles descubrieron el suelo americano, los pampas eran empujados hacia el norte por los araucanos salvajes que venían de Chile" (Arriola, s/f:.5).

a.2) El indígena "bárbaro" en un territorio transformado

Los indígenas son despojados de las categorías del tiempo y del espacio y se transforman en ahistóricos. Su lugar en los textos no está vinculado a los acontecimientos de la historia nacional, sino a la arqueología y la prehistoria, pero no en el sentido del origen, sino de un pasado remoto sin vínculos con la cultura nacional o solamente asociados como vestigios.

"En algunas regiones de nuestro país especialmente en el norte y en el sur, existen todavía muchos indios que, aunque mantienen relaciones de paz y de trabajo con los blancos, en el fondo se conservan fieles a sus viejas tradiciones" (Berdiales e Inchauspe 1942-1959:10).

Asimismo, en los textos analizados aparece también la categorización del indígena como "bárbaro". En ellos pueden considerarse dos perspectivas en el tratamiento del problema; por un lado, el indígena ha sido superado por la civilización, en otras palabras, eliminado: el indio ya no existe, pertenece a un pasado no necesariamente nacional sino "prehistórico": "Los primitivos habitantes de nuestro territorio fueron los indios", narra una lectura para niños de segundo grado. En esta lectura predominan los verbos en pasado cuando relata usos y costumbres de las tribus "semisalvajes": "vivían, se alimentaban, cazaban, navegaban" (M aimó 1942:5).

Por otro, si bien la "barbarie" ubica al indígena en el extremo opuesto de la "civilización" y funciona como parámetro de exclusión, sin embargo no obstaculiza, una vez controlada, la posibilidad de inclusión a la civilización, aunque en términos de manifiesta desigualdad. Se incluye homogeneizando, borrando las diferencias culturales, y/o se incluye invisivilizando-naturalizando las desigualdades para constituir la Nación y ocupar el espacio que se transformó en fértil y productivo.

En este punto, los parámetros de igualdad y desigualdad con la cultura blanca, en términos de subordinación e inferioridad cultural, coinciden con los textos salesianos aunque en estos textos la "invisibi- 
lización" se evidencia en menor medida gracias a la fundamentación teológica que sostiene la igualdad de todos los hombres redimidos por el bautismo bajo una misma institución: Ia Iglesia Católica, idea que fundamentó el fundador de la Congregación D on Bosco (N icoletti 2005).

\section{a.3) El indígena "arqueologizado" en clave natural}

Cuando el indígena no aparece mirado a través de las categorías impuestas como "salvaje" o "bárbaro", obstáculo al progreso, en oposición a la "civilización", su tratamiento, pasa en los textos a categorías que lo inmovilizan, lo arqueologizan o paleontologizan (Q uijada 1998 y 1999). En ese sentido, los indígenas

"más que sociedades estudiadas en clave histórica son entidades comprendidas en clave natural. A esto se suma que, como entidades naturales, son incorporadas a una visión estática de la naturaleza que no implica el cambio presupuesto en una visión evolucionista de la misma. En consecuencia, la diversidad cultural no es estudiada en su genealogía sino en su condicionamiento ecológico-ambiental" (Podgorny b 1999:100).

Aparecen así descriptos como:

"Los hombres civilizados cuando quieren perpetuar un hecho importante levantan monumentos o escriben un libro; en el mismo caso, nuestros indios que tienen un alma simple, no saben esculpir, ni escribir, forjan una leyenda. Casi siempre son relatos ingenuos en los que se trata de explicar el origen de las cosas; otras veces son de carácter cómico e intervienen en ellos animales de nuestra fauna y seres sobrenaturales de toda especie" (Berdiales e Inchauspe 1942-1959:11).

En función del concepto de "apropiación" que define Andermann" (Andermann 2000: 124-125), los habitantes de la Patagonia aparecen paleonteologizados o arqueologizados, según define Mónica Q uijada (1998 y 1999). En otras palabras, si bien se revalorizaba el entorno natural, sus habitantes se "inmovilizaban" quedando relegados a la

6 Dispositivo que reivindica la tradición de tomar posesión, mediante la letra, de tierras que hasta el momento habían estado fuera de su alcance, en nombre de los valores que esta letra representa: la cultura, la civilización, la productividad (Andermann 2000:102). 
memoria como lo que ya fue, en especial como sujetos conquistados, evangelizados, civilizados y en definitiva invisibilizados, cuestionándose su existencia y por consiguiente su posibilidad de integrarse al territorio nacional como ciudadanos (Q uijada 1999 y Navarro Floria 2003) a lo sumo podrían integrarse como "indios argentinos" (Delrío 2005). La cuestión de la destribalización e invisibilización de los indígenas entre 1904 y 1916 tuvo una estrecha relación, como afirma Delrio, con el problema de la apropiación de las tierras y la tenencia precaria de las mismas.

En los textos escolares, como Nuestra Tierra, los aborígenes de la Patagonia son objeto de una operación discursiva que los ubica en los límites de la desaparición física o bien en la asimilación absoluta:

"Hoy día los indios visten y viven más o menos como el resto del pueblo; muchos hablan nuestra lengua y son buenos amigos de los blancos, si bien quedan todavía algunas tribus rebeldes que tiene sus madrigueras en parajes deshabitados de las selvas y montañas" (López de Nelson 1912/16: 33).

Como señala Artieda,

"Las lecturas escolares recrearán esta imagen con diferentes recursos como el de citar a los aborígenes como un elemento más del paisaje natural, compararlos con animales o tormentas o detenerse en una descripción exhaustiva de sus características físicas y explicar su carácter en función de la geografía que habitan" (Artieda 2004:5).

\section{a.4) El indígena clasificado}

Los textos seleccionados muestran al indígena dentro de clasificaciones raciales con características culturales que los agrupa y que incluso muestran distintos grados de "civilización" de acuerdo a sus actividades económicas (cazadores, recolectores, agricultores, etc.), políticas (si habitaban en tribus y tenían cacique) y sociales.

El texto de Arriola señala esta clasificación: Los Araucanos y los patagones...

"Las tribus del sur, Ilamadas patagones por los españoles, trabaron relaciones con los araucanos y se mezclaron con ellos. Eran tribus errantes que tenían por vivienda toldos de cuero que lle- 
vaban de una parte a otra. Conocían algo de agricultura y de las artes manuales: su industria principal era la fabricación de tejidos. Para vestirse usaban ponchos y mantas. Se adornaban con collares y pulseras y se pintaban la cara. Su alimento era la carne del guanaco, del peludo y del avestruz. Sobresalían en la guerra. Abrían trincheras y fosos y edificaban fortalezas. Para mejor combatir buscaban siempre, antes de presentar combate, el terreno más adecuado para desarrollar su plan de batalla. Los patagones vivían cerca de Tierra del Fuego. Eran pocos, pero llamaban la atención por su elevada estatura" (Arriola s/f: 5 y 6).

A continuación, el texto presenta un cuadro sinóptico con el título "Primeros habitantes de la Argentina", que contiene los siguientes subtítulos: "La Argentina antes del descubrimiento", "los quichuas", "Ios guaraníes", "los pampas", "los araucanos", "los patagones". Las únicas referencias sobre éstos últimos es que vivían cerca de Tierra del Fuego, eran de elevada estatura. Los araucanos en cambio, provenientes de Chile, son caracterizados como célebres guerreros, altivos y sin miedo (Arriola s/f:7).

El libro de C. Cánepa, bajo el título "Naciones de Indios que habitaban el país en la época del descubrimiento", hace una clasificación agrupándolos geográficamente: grupos del litoral, grupos del centro y grupos occidentales. Entre estos últimos aparecen identificados para la Patagonia los "moluches" o araucanos que incluían a los pehuenches "de la misma estirpe que los famosos araucanos de Chile". Finalmente menciona cerca de Usuhaía a los "Yahganes" o "yámanas", "que representan a los antiguos habitantes de la Patagonia". (Canepa 1912:26).

A estos grupos el autor los identifica como "habitantes" integrantes de "naciones". La primera enunciación remite a los orígenes (habitantes antes del descubrimiento). La segunda, al concepto de Nación no en el sentido político jurídico, sino por rasgos fenotípicos y psicológicos invariables que Alcides d'Orbigny (1802-1857) denominaba "carácter nacional" y calificaba como "raza" americana dividida en "ramas" y subdividida en "naciones", a su vez fraccionadas en "tribus" u "hordas" más o menos salvajes. La "invariabilidad se vuelve legitimación de la conquista, cuando las naciones descriptas son 'salvajes' errantes por el 'desierto'" (Navarro Floria y Roulet 2005: 32).

Significativamente, los únicos que aparecen mencionados en tiempo presente son los "yámanas" de Tierra del Fuego. En este enunciado reconoce la existencia presente de esa nación fueguina, aunque 
en proceso de extinción si atendemos al año de edición del texto, y como representación de los que ya no están, de los antiguos habitantes del territorio.

b) Iguales pero distintos: la construcción del indígena "infiel" en los textos salesianos

Si bien los textos salesianos se ajustaron al esquema oficial descripto introdujeron algunas variantes que los diferenciaban de los textos oficiales, relacionadas con la inserción del pensamiento católico.

La clara adhesión al creacionismo y al evolucionismo sociocultural del que participaba la Iglesia de la época, tenía su correlato en la fundamentación que Don Bosco realizaba de la evangelización indígena cuando adhiere a la tradición misionera fundada en el siglo XVI, al afirmar la unicidad del género humano y la asignación de la culpa de los "hábitos salvajes" al demonio (demonización), lo que suponía a los indígenas víctimas y no culpables. Las posibilidades de redención estaban para Don Bosco claramente enunciadas: Dios a través de la Congregación Salesiana podía proveer misioneros, que siguiendo el plan presentado, los evangelizaran y educaran para lograr la única posibilidad de salvación (Nicoletti 2005). Esto no significaba que no adhiriera a la categorización de "salvaje" que aparece profusamente en sus escritos.

U na categoría propia del pensamiento decimonónico y de la Iglesia de su tiempo: ser cristiano es ser civilizado. Además, y para que no queden dudas de esta adscripción, los textos justifican el monogenismo a través de: "las tradiciones de los pueblos", "los inventos de la filología", "la literatura" y "los narradores históricos más antiguos" calificando como "inadmisibles" las teorías poligenistas en base a las diferencias de "color" de "cabello" y la "configuración del cráneo" (Compendio de Geografía U niversa: 61).

Fiel al magisterio de la Iglesia y a las directrices del Concilio Vaticano I (1869)7, Don Bosco fue construyendo a través de sus "sueños" 8

7 Básicamente advertimos los siguientes postulados en relación a la misión ad gentes: La unidad en Cristo, el trabajo misionero por la unidad, el mandato de Cristo de predicar el Evangelio y finalmente el hombre en general como destinatario de este anuncio cuyo fin es alcanzar la salvación de las almas. Estas están delante de Dios privadas de toda culpa, pues viven en la ignorancia invisibles al reparo de Cristo y su Iglesia y se mueven según el principio de la ley natural que Dios ha esculpido en el corazón de todo hombre (Favale 1976).

8 Don Bosco tuvo a lo largo de su vida lo que él mismo y después la Congregación salesiana denominó "sueños", que fueron visiones que han llegado hasta nosotros a través de su relato 
y de la información científica disponible en Europa sobre la Patagonia, este concepto del indígena "infiel" como base y justificación de su tarea misionera. Concepto que enunció en reiteradas oportunidades ante el Colegio De Propaganda Fide por medio de sus informes (Ceria 1959) y de su escrito central La Patagonia e le terre australi del Continente americano (1876).

Desde esta fundamentación se exculpó a los indígenas de su "naturaleza indómita", separándose de las afirmaciones del autor del que principalmente se sirve en su informe ${ }^{9}$, para categorizarlos como "infieles", desconocedores de la verdad por ignorancia y no por falta de inteligencia (Bosco 1988). Este concepto incluía la posibilidad de aprendizaje de cada grupo indígena, de acuerdo a las teorías ambientalistas vigentes en la época.

Esta premisa partió seguramente de la convicción, común en las ideas de la época, que algunos grupos humanos carecían de una verdadera capacidad de intelección por no poseer los recursos culturales adecuados de la ciencia moderna (Geert 2000). Coincidiendo además con la categorización de minoridad que desde la ley el Estado le imponía al indígena, los misioneros consideraban que "un indio adulto es simplemente un niño grande" (Marabini 1906), de allí que el sistema de reducciones o colonias fuera la opción más buscada y el concepto de "civilización"10 como grado máximo del progreso.

El texto escolar reafirma este concepto, "todos los hombres son iguales", porque comparten un mismo creador pero se encuentran en diferentes "estado(s) de civilización" y presentan como el parámetro de "civilización" a los pueblos "cristianos", que "constituyen los pueblos mas civilizados de la Tierra". (Pequeña Geografía).Como señala Teresa Artieda, los textos escolares en el caso de la evangelización "sostiene la imagen del sujeto igual pero incompleto" (Artieda 2004:7).

directo a los miembros de la Congregación y muchos de ellos corregidos de su puño y letra, tienen diferentes versiones de acuerdo a quien haya hecho el registro. Estos "sueños", tenían una finalidad pastoral y eran presentados en forma de relato a los jóvenes y salesianos a los que Don Bosco predicaba. No analizamos aquí la naturaleza de los mismos, de la que existe una profusa bibliografía con diferencias en cuanto a su interpretación, sino a los conceptos que de estos relatos se desprenden en función del tema. En otro trabajo hemos analizado una serie de cinco "sueños" $(1872,1878,1883$, y 1885) en los que advertimos la confección del concepto del indígena "infiel" y el proyecto de evangelización para la Patagonia (Nicoletti, 2005).

9 Nos referimos a Alcides d' Orbigny que en su obra "Viaje a la América Meridional” presenta la invariabilidad del "carácter" y por lo tanto las costumbres de los indígenas (Bosco 1988).

10 Idea generada principalmente por François Guizot (1787-1874) y Claude Saint-Simon (1760$1825)$. 
¿Cómo pensaban remediar los Salesianos esta diferencia en el caso de los indígenas patagónicos, representantes de la "raza cobriza"? Milanesio propuso a la educación en el trabajo agrícola y fundamentalmente la educación en la fe católica, como herramienta vital para el progreso en la "civilización". Esta posibilidad estaba latente en el reconocimiento de una humanidad indígena contenida en una ley natural en estado puro, pero "algo entorpecida". Para que los indígenas pudieran desarrollar estos principios incompletos y convertirse efectivamente en "buenos cristianos" y "buenos ciudadanos", la acción misionera y educativa resultaba pues indispensable. La prédica misionera los ayudaba entonces a "perfeccionarse paulatinamente tanto en el orden moral como material" (M ilanesio 1890).

Los textos salesianos no escapan al tratamiento de la "arqueologización" del indígena que se visualiza en Historia Argentina, curso elemental del salesiano J. Fuchs, cuando menciona como primer habitante de la Argentina al grumete Francisco del Puerto, recogido por Gaboto, que vivió diez años "entre los indios" (p. 16), desconociendo de este modo, a los indígenas como pobladores originarios y ubicando los orígenes de la Nación en la conquista española. Los indígenas que poblaban el territorio argentino se encontraban en "estado salvaje", diferenciándose entre sí, como ya advertimos, por un claro determinismo geográfico y cultural. La clasificación por regiones los agrupa, simplifica e inmoviliza.

En la descripción de las campañas militares, los libros de textos salesianos que analizamos nos muestran al indígena de la Patagonia en el escenario de la lucha entre "salvajes" y "civilizados". Una lucha que no es uniforme en los dos períodos denominados "Expedición al desierto".

La Patagonia de la época de Avellaneda ya no es un territorio "salvaje" y "fronterizo", es por el contrario un producto de la Nación, pero por sobre todo, es un territorio en el que no hay más "salvajes" sino "indios reducidos", y fundamentalmente "bautizados". Para los Salesianos, la Patagonia, además de ser un territorio nacional es un territorio católico producto de la acción salesiana.

En este texto se introduce la problemática de la evangelización y la reducción de la polémica suscitada dentro de la Congregación, ante la situación del avance del ejército argentino y la violencia sobre los indígenas a los que efectivamente bautizó Santiago Costamagna (ACS, 203.1:23/12/1879). Juan Bosco, el fundador de la Congregación, al 
enterarse de este suceso escribió inmediatamente a los misioneros salesianos objetándoles el ingreso con el ejército y lamentando la situación de violencia (Lemoyne-Amadei y Ceria 1981-1989).

En los textos analizados, las categorías en las que devienen las etapas históricas ("salvajes"y "arqueologizados"), aparecen yuxtapuestas, pero si además comparamos los textos salesianos con los textos de las escuelas oficiales, la introducción de la variable misionera suma a estas categorías la del indígena "infiel", "bautizado", "reducido" y "redimido". Un indígena que se incorpora a la "civilización" porque es hijo de la Iglesia deja entonces de representar un "peligro para el progreso".

\section{Conclusiones}

Los textos escolares como herramientas de construcción y socialización discursiva nos permiten analizar la construcción territorial de la Patagonia, en el marco del conflictivo proceso de su incorporación a la Nación argentina, en clave hegemónica y "argentinizadora".

Las categorías de "desierto" y de espacio "vacío" institucionalizaron una imagen acorde con el discurso científico que contribuyó a la internalización del territorio como uno de los componentes de la ideología colectiva nacional. La imagen de la Patagonia reflejada en los textos analizados, tanto oficiales como salesianos, no responde a la transposición de los conocimientos científicos de la época sino más bien a la funcionalidad política que buscaba "canonizar una imagen unificada del país y de su territorio". La construcción del espacio y sus habitantes aparecen en clave dicotómica: el desierto y la civilización, lo explorado y lo inexplorado, lo bárbaro/salvaje y civilizado, el "vacío" improductivo y la tierra fértil. Esta ha sido la matriz que recorre la caracterización de cada uno de los territorios patagónicos y contrapone los términos fértil/infértil, conocida/desconocida y explorada/inexplorada, mostrándonos a una Patagonia de principios de siglo inserta en la clásica conceptualización: "civilizada/incivilizada".

Sus habitantes han sido analizados en función del espacio como "salvajes" en el contexto de la "conquista", como "bárbaros" en un territorio transformado y "arqueologizados" en clave natural. Por otro lado desde la perspectiva de la inclusión social del indígena, en el discurso hegemónico existen algunas versiones que lo consideran como 
sujeto pero con características desiguales respecto del blanco. Su incorporación social se entiende en términos de inferioridad y marginalidad. A veces se lo invisibiliza, otras se lo "proletariza", ubicándolo en un sector social de marginación y pobreza, excluyéndolos como ciudadanos integrados al colectivo nacional.

Por otro lado los textos salesianos, adhirieron también a la categorización de "salvaje" que aparece profusamente en sus escritos, pero fundamentaron esta inferioridad del "otro" en la asignación de la culpa de los "hábitos salvajes" al demonio (demonización), lo que suponía a los indígenas víctimas y no culpables. En otras palabras, en función de la unicidad del género humano, que sostenía la igualdad entre los hombres, el indígena, bautizado, hijo de la Iglesia, era pasible de educación y civilización.

\section{Corpus Documental}

1. DALL'ERA, Cesare, Brevísima reseña de Historia patria. Escuela Tipográfica Salesiana del Colegio Pío IX de Artes y O ficios. Segunda edición. Cuarta y quinta edición. 1896.

2. Pequeña Geografía con arreglo al Programa de tercer grado. Buenos Aires. Escuela Tipográfica Salesiana del Colegio Pío IX de Artes y Oficios. 1908.

3. Elementos de Geografía con arreglo al Programa de tercer grado. Buenos Aires. Escuela Tipográfica Salesiana del Colegio Pío IX de Artes y O ficios (circa, 1900).

4. La Historia Argentina de los niños en cuadros. Edición del Centenario 1910. Buenos Aires, Lajouane, 1910.

5. Compendio de Geografía con arreglo al Programa de tercer grado. Buenos Aires. Escuela Tipográfica Salesiana del Colegio Pío IX de Artes y O ficios. 1911.

6. CÁNEPA, Carlos. La Historia Argentina. Desde el descubrimiento hasta nuestros días. Cabaut editores. Buenos Aires. 1912.

7. CARBIA, Rómulo. Manual de Historia de la Civilización argentina. Buenos Aires, UBA, 1912.

8. LÓ PEZ DE NELSON, Ernestina. Nuestra Tierra. Libro de Lectura para cuarto grado, s/f circa 1912/16. 
9. RAVIO L, Luis. Compendio de Geografía de América. Buenos Aires. Cabaut. 1913.

10. BLOM BERG, Héctor. Pensamiento. Libro de Lectura para cuarto grado. Buenos Aires, Estrada, 1925.

11. BLO M BERG, Héctor. El Sembrador. Buenos Aires. 1925.

12. CALDERARO, José. Las horas emotivas. Libro de lectura para 5 y 6 grado. Cabaut editores, Buenos Aires, 1927.

13. PIZZURNO, Carlos. Lecciones de Historia Argentina. Buenos Aires, Crespillo, circa 1930.

14. FUCHS, J (circa 1934), Historia argentina. Curso elemental. Librería del Colegio Pío IX.

15. BRAÑA DE IACOBUCCl, Blanca y IACOBUCCl, Guillermo. Fuentes de vida. Libro de Lectura para sexto grado, Buenos Aires, Kapelusz, 1937 (primera edición), 1958.

16. CAPDEVILLA, Arturo y G ARCíA BELLOSO, Julián. Nueva Jornada. Texto de Lectura para cuarto grado. Buenos Aires, Kapelusz, 1937.

17. SÁENZ VALIENTE, José María. Curso de historia Colonial Americana y especialmente Argentina. Buenos Aires, Estrada. 1939.

18. CASTILLO, José (dir).Revista de Instrucción Primaria. La Plata, enero de 1939, № 805 y 806.

19. DAG NINO PASTORE, Lorenzo. Geografía para IV año. Crespillo, Buenos Aires, 1940.

20. Libro de Lectura. Circa 1940-1950.

21. TO LOSA, O scar. Cielo Azul, Libro de Lectura. Arai, 3 era. Edición, 1940.

22. Enciclopedias escolares. Atlántida, Buenos Aires. T I y T II. Para cuarto, quinto y sexto año. 1941.

23. ESTRELLA GUTIÉRREZ, Fermín. Días de Infancia. Libro de Lectura para cuarto grado. Buenos Aires, Kapelusz, 1942.

24. MAIM Ó, D ora. Delantales blancos. Libro de lectura para segundo grado. Buenos Aires, Sastre, 1942. 
Mirta Teobaldo y María Andrea Nicoletti

25. PEDOTTI, César. Libro de Lectura para cuarto grado. Buenos Aires, Don Bosco, 1955. Primeras ediciones 1942-43.

26. GÓMEZ, Miguel Ángel. Alma y Belleza, Libro de lectura para sexto grado. Buenos Aires, Kapelusz, 1942-1951.

27. BERDIALES, Germán y Inchauspe, Pedro. Nuevo Mundo. Lecturas para quinto grado. Buenos Aires, Kapelusz, Primera edición 1942, séptima edición, 1959.

28. La O bra. Revista de Educación. № 395, 1943.

29. La O bra. Revista de Educación №445, 1946.

30. Panoramas de América. Libro de Lectura para quinto grado. 1era. Edición 1942. 1960.

31. ARRIOLA, C. Historia de la cultura argentina. Buenos Aires, Stella, s/f.

\section{0 tras fuentes documentales}

Archivo Central Salesiano, Caja 203.1, carta de S. Costamagna a Don Bosco, Patagones 23 de junio 1879.

Archivo Histórico de las Misiones Salesianas de la Patagonia Norte, Milanesio, Domenico. Rasgos etnográficos de los indígenas de la Patagonia, Imperiosa necesidad de educarlos, 1890.

BOSCO, Giovanni La Patagonia e le Terre Australi del Continente americano, Roma, LAS. Texto crítico Borrego, J sdb. 1988.

CERIA, Eugenio (a cura di), Epistolario di San Giovanni Bosco, vol IV, (1881-88), Torino, SEl, 1959.

M ARABINI, Pedro (1906) Los Salesianos del Sud. Trabajos y riquezas. Contestación al Informe "Las escuelas del sud" del Dr. J.B. Zubiaur, vocal del Consejo Nacional de Educación. Buenos Aires, Pío IX.

LEM OYNE, J; AMADEI, A.; CERIA, E., Memorias biográficas de San Juan Bosco. Tomos XVII y XVIII, Madrid, CCS. 1981-1989.

Programas escolares de los seis grados de la Educación común para las clases de aplicación de las escuelas normales de la Nación arreglados para los colegios de la Obra de Don Bosco en la República Argentina, Buenos Aires, Pío IX,1907. 


\section{Bibliografía}

AN DERM AN N, Jens (2000) M apas de poder. U na arqueología literaria del espacio argentino, Buenos Aires, Viterbo.

ARTIEDA, Teresa (2004) “El 'otro más otro' o los aborígenes americanos en los textos escolares. Una propuesta de análisis", en: GUEREÑA, L., O SSEN BACH , G . y DEL PO ZO , M .M. (eds.), M anuales escolares en España, Portugal y América Latina (Siglos XIX y XX), Madrid, UNED (Serie "Proyecto MANES"), pp. 485-501.

BRIONES, Claudia y DELRIO, Walter (2002) "Patrias sí, colonias también. Estrategias diferenciadas de radicación de indígenas en Pampa y Patagonia", en: TERUEL, Ana y otros (comp.), Fronteras, ciudades y estados, Córdoba, Alción. pp. 45-78.

CUCUZZA, Héctor y PINEAU, Pablo (2002) Para una historia de la enseñanza de la lectura y escritura en Argentina. Del catecismo colonial a La Razón de Mi Vida. Buenos Aires, Miño y Dávila.

DELRIO, W alter (2005) Memorias de expropiación. Sometimiento e incorporación indígena en la Patagonia, 1872-1943, Buenos Aires, Universidad Nacional de Q uilmes.

FAVALE, Antonio (1976), II Progetto missionario di Don Bosco e suoi presupposti storico-dottrinali, in «Salesianum» 3904.

GEERTZ, Clifford (2000) La interpretación de las culturas. Barcelona, Gedisa.

KAUFMANN, Carolina. (2002/03), "Producciones sobre textos escolares argentinos: hitos, tendencias y potencialidades", en: Anuario de Historia de la Educación, № 4, pp. 37-60.

LACOSTE, Pablo (2001) "Mapas territoriales e imagen del país vecino: el caso de Argentina y Chile", en: BANDIERI, Susana (coord.) Cruzando la cordillera. La frontera argentino-chilena como espacio social, U N C, Neuquén, pp. 191-229.

LEÓN SOLÍs, Leonardo y VILLALOBOS, Sergio (2002), "Tipos humanos y espacios de sociabilidad en la frontera mapuche de Argentina y Chile (1890-1900)", en: Estudios historiográficos, 1, $2^{\circ}$ semestre, pp. 85-114. 
NAVARRO FLORIA, Pedro (2001) "El salvaje y su tratamiento en el discurso político argentino sobre la frontera sur, 1853-1879", en: Revista de Indias, LXI-222 mayo-agosto, pp. 346-376.

NAVARRO FLORIA, Pedro (2002) "El desierto y la cuestión del territorio en el discurso político argentino sobre la frontera sur", en: Revista Complutense de Historia de América, 28, pp. 139-168.

NAVARRO FLORIA, Pedro y ROULET, Florencia (2005) "De soberanos externos a rebeldes internos: la domesticación discursiva y legal de la cuestión indígena en el tránsito de los siglo XVIII al XX", en: Revista Tefros (en publicación).

NICOLETTI, María Andrea (2005) "Evangelizar y educar a los indígenas en la Patagonia: conceptos claves de Giovanni Bosco y sus misioneros salesianos", en: Espacios. Historia, política y educación. Río Gallegos, 4.

PODGORNY, Irina (1999a) Arqueología de la educación. Textos, indicios, monumentos". Buenos Aires. Sociedad Argentina de Antropología.

- (1999b), "La Patagonia como santuario natural de la ciencia finisecular", en: Redes, Revista de estudios sociales de la ciencia, vol. 6, № 14, pp. 157-176.

PRATT, Mary Lois (1992) Ojos imperiales. Literatura de viajes y transculturación. Buenos Aires. Universidad Nacional de Quilmes.

QUIJADA, Mónica, BERNARD, Carmen, SCHEIDER, Arnd (2000), Homogeneidad y Nación: con un caso de estudio: Argentina Siglo XIX y XX. M adrid. CSIC.

- - (1998), "Ancestros, ciudadanos y piezas de museos. Francisco Moreno y la articulación del indígena en la construcción nacional argentina", en: Estudios interdisciplinarios de América Latina, 9:2, pp. 20-46.

- - (1999), "La ciudadanización del 'indio bárbaro' políticas oficiales y oficiosas hacia la población indígena de La Pampa y la Patagonia, 1870-1920", en: Revista de Indias, LIX-217, pp. 675-704.

RO M ERO, Luis Alberto (coord.) (2004), La Argentina en la escuela: La idea de nación en los textos escolares. Buenos Aires, Siglo XXI. 
QUINTERO, Silvina (2002) "Geografías regionales en la Argentina. Imagen y valorización del territorio durante la primera mitad del siglo XX", en: Scripta Nova. Revista electrónica de geografía y ciencias sociales, VI, N o 127, 15 de octubre de 2002.< http://www. ub.es/geocrit/sn/sn-127.htm> .

TEOBALDO, Mirta y GARCÍA, Amelia (2003) "Estado y Sociedad Civil en la conformación y desarrollo del sistema educativo en el Territorio Nacional de Río Negro, 1884-1945", en: PUIGGRÓS, Adriana. La educación en las provincias y Territorios Nacionales (1884-1945), Buenos Aires, Galerna.

\section{Resumen}

La Patagonia, como tierra mítica, y sus habitantes originarios, han sido objeto de diferentes estudios. Sin embargo, su representación a través de los libros de texto es tema escasamente estudiado. En base a un corpus de catorce libros de textos, correspondientes a las escuelas del Estado y a las escuelas de la Congregación salesiana, nos proponemos analizar dos representaciones específicas sobre el indígena patagónico: 1) el indígena como "salvaje" y "enemigo de la civilización" en un espacio "vacío" y "desierto" y 2) el indígena "paleontologizado" y ahistórico, en un espacio natural con potencial productivo. Las representaciones están vinculadas a dos ideas relacionadas con las políticas del Estado sobre la Patagonia: una con el plano territorial: la idea de "desierto" y "vacío" y la otra, con el plano de sus habitantes: la idea de "salvajismo" y "barbarie"; ideas que legitiman la conquista y el exterminio de sus habitantes originarios. En los textos escolares la transposición didáctica operó yuxtaponiendo nuestras categorías de análisis.

Palabras claves: textos escolares, Patagonia, indígenas, representaciones.

\section{Representations on Patagonian native peoples in school text- books. 1886-1940. \\ Summary}

The Patagonia, like a mythical land and their native inhabitants, has been analyzed through different studies. N evertheless, its representation through the textbooks is a topic scarcely studied. Based on a 
corpus of fourteen textbooks, belonging to State and Salesian schools, we intend to analyze two specific representations on Patagonian natives: 1) the native as "savage" and "enemy" of the "civilization" in a "empty" space, a "desert" and 2) the native "paleontologizado", without history, in a natural space with productive potential. The representations are linked to two ideas related to the political ones of the State on the Patagonia: one with the territorial level: the idea of "desert" and "emptiness" and other one, with that of its inhabitants: the idea of "savagery" and "barbarism", such ideas being useful to legitimize the conquest and the extermination of its native inhabitants. In the textbooks the didactic transposition operated overlaping our categories of analysis.

Key words: textbooks, Patagonia, native peoples, representations. 